\title{
Pengembangan Multimedia Interaktif Menggunakan Aplikasi Ispring Suite 9 Pada Pembelajaran IPA Kelas IX Di SMP Negeri 5 Panyabungan
}

\author{
Maisyarah Purnama Sari dan Ridwan \\ Universitas Negeri Padang \\ E-mail : maisyarahpurnama@gmail.com dan ridwanftunp@gmail.com \\ Diterima: Mei 2020 ; Dipublikasikan Juli 2020
}

\begin{abstract}
ABSTRAK
Fasilitas pendukung pembelajaran di SMP Negeri 5 Panyabungan sudah memadai untuk proses pembelajaran peserta didik, namun inovasi belum maksimal yang memanfaatkan teknologi untuk proses pembelajaran. Penelitian ini bertujuan mengetahui pengembangan dan kelayakan multimedia interaktif menggunakan aplikasi ispring suite 9 terhadap hasil belajar pada mata pelajaran IPA dalam bentuk pembelajaran menggunakan perangkat komputer ataupun laptop yang dapat dioperasionalkan secara offline. Jenis penelitian ini merupakan Research and Development (R\&D) dengan menggunakan model pengembangan ADDIE. Penilaian ahli media, ahli materi, ahli bahasa, peserta didik dan guru digunakan sebagai data penelitian dan dianalisis dengan deskriptif persentase. Berdasarkan penelitian ini diperoleh produk dengan penilaian ahli materi sebesar $96 \%$, ahli media sebesar $88 \%$, ahli bahasa sebesar $82,5 \%$, tanggapan peserta didik sebesar $90 \%$; dan tanggapan guru sebesar 95\%. Berdasarkan hasil penelitian tersebut dapat disimpulkan bahwa multimedia interaktif menggunakan aplikasi ispring suite 9 pada mata pelajaran IPA layak digunakan sebagai media pembelajaran peserta didik kelas IX SMP.
\end{abstract}

Kata Kunci: multimedia interaktif, ispring suite 9, pembelajaran ipa

\begin{abstract}
Learning support facilities in SMP 5 Panyabungan are sufficient for the learning process of students, but innovation has not been maximized that utilizes technology for the learning process. This study aims to determine the development and feasibility of interactive multimedia using the Ispring suite 9 application on learning outcomes in natural science subjects in the form of learning using a computer or laptop that can be operated offline. This type of research is a Research and Development (R\&D) using the ADDIE development model. Assessment of media experts, material experts, linguists, students and teachers is used as research data and analyzed with descriptive percentages. Based on this research, a product with a material expert judgment of $96 \%$ was obtained, media expert was $88 \%$, linguist was $82.5 \%$, student responses were $90 \%$; and teacher responses by $95 \%$. Based on these results it can be concluded that interactive multimedia using the ispring suite 9 application on natural science subjects is suitable as a learning medium for students of grade IX junior high school.

Keywords: interactive multimedia, ispring suite 9 , natural sciences learning
\end{abstract}

\section{PENDAHULUAN}

Pendidikan merupakan sektor yang sangat menentukan kualitas suatu bangsa. Pendidikan memberikan arahan kepada siswa untuk mempelajari berbagai hal tentang kehidupan, guna mampu menjadi pribadi yang tangguh dalam menghadapi masa depan, dan setiap masyarakat Indonesia hendaknya mengecap pendidikan yang layak. Sejalan dengan UU RI Nomor 20 Tahun 2003 poin C tentang Sistem Pendidikan Nasional, menyatakan bahwa "Sistem Pendidikan Nasional harus mampu menjamin pemerataan kesempatan pendidikan, peningkatan mutu serta relevansi dan efisiensi manajemen pendidikan untuk menghadapi tantangan sesuai dengan tuntutan perubahan kehidupan lokal, nasional, dan global sehingga perlu dilakukan pembaharuan pendidikan secara terencana, terarah dan berkesinambungan." Menghadapi tantangan global, dunia pendidikan menuntut untuk dilakukannya inovasi dan kreatifitas yang dapat mendukung peningkatan mutu pendidikan. Perkembangan teknologi sejalan dengan peningkatan mutu pendidikan yang tertuang dalam Peraturan Pemerintah nomor 19 tahun 2005 pada bab 4 tentang Standar Nasional Pendidikan mengenai standar proses, menyatakan bahwa "Proses pembelajaran pada satuan pendidikan diselenggarakan secara interaktif, inspiratif, menyenangkan, menantang, memotivasi siswa untuk 
berpartisipasi aktif, serta memberikan ruang yang cukup bagi siswa untuk membentuk kreativitas, dan kemandirian sesuai dengan bakat, minat, dan perkembangan fisik serta psikologis siswa."

Pemerintah mencanangkan pendidikan secara merata dilakukan di seluruh wilayah Indonesia, baik di perkotaan maupun di pedesaan. Pendidikan yang dimaksudkan merupakan pendidikan yang layak, dengan memberikan pembelajaran secara interaktif, inspiratif, menyenangkan, menantang, serta memotivasi siswa untuk berpartisipasi aktif sehingga menimbulkan kreativitas dan kemandirian. Sistem pendidikan di sekolah mengajarkan banyak mata pelajaran. Salah satu mata pelajaran yang diajarkan di sekolah adalah mata pelajaran Ilmu Pengetahuan Alam (IPA). Mata pelajaran IPA berkaitan dengan cara mencari tahu tentang alam secara sistematis, sehingga IPA bukan hanya kumpulan pengetahuan yang berupa fakta-fakta, konsep-konsep, atau prinsip-prinsip saja tetapi juga merupakan suatu proses penemuan. Permen Diknas Nomor 22 Tahun 2006 "Pembelajaran IPA sebaiknya dilaksanakan secara inkuiri ilmiah (scientific inquiry) untuk menumbuhkan kemampuan berfikir, bekerja dan bersikap ilmiah serta mengkomunikasikannya sebagai aspek penting kecakapan hidup. Oleh karena itu pembelajaran IPA di SMP/MTs menekankan pada pemberian pengalaman belajar secara langsung melalui penggunaan dan pengembangan keterampilan proses dan sikap ilmiah."

Menurut Permen Diknas Nomor 22 Tahun 2006 di atas, pembelajaran IPA sebaiknya dilakukan dengan lebih mendekatkan siswa kepada pengalaman belajar langsung, untuk meningkatkan keterampilan, dan sikap ilmiah. Pengalaman belajar langsung sangat baik untuk siswa, akan tetapi dalam beberapa situasi dan kondisi pengalaman belajar langsung tidak memungkinkan untuk diberikan kepada siswa. Seperti pada materi ajar IPA kelas IX, yaitu sistem reproduksi pada manusia, sistem perkembangan tumbuhan dan hewan sangat sulit untuk menjangkau pembelajaran langsung. Penggunaan alat peraga yang terbatas, menjadikan pembelajaran belum efektif. Siswa yang terdekat dari jangkauan alat peraga yang digunakan dapat melihat jelas, dan memahami penjelasan guru. Siswa dengan jumlah yang banyak dalam satu kelas akan membutuhkan waktu yang banyak untuk melaksanakan pembelajaran dengan lebih efektif jika dituntut untuk memberikan pengalaman belajar secara langsung kepada siswa.

Berdasarkan hasil wawancara yang dilakukan pada siswa kelas IX SMP Negeri 5 Panyabungan, kendala dalam pembelajaran IPA adalah sulit memahami gambar yang tersaji pada buku teks karena tersaji dalam bentuk potongan-potongan bagian dari bentuk yang dijelaskan. Siswa mengharapkan pembelajaran dilakukan dengan media agar pembelajaran menarik dan menyenangkan, sehingga siswa termotivasi dalam proses pembelajaran. Berdasarkan hasil wawancara dengan guru IPA mengatakan bahwa proses pembelajaran telah dilakukan sesuai tujuan pembelajaran, yakni sesuai dengan kurikulum, silabus dan pengembangan RPP namun penggunaan media pembelajaran di kelas belum terlaksana secara optimal. Hal ini dikarenakan media pembelajaran berupa alat peraga terbatas, dan terkadang dalam penggunaannya diletakkan di meja depan kelas agar alat peraga tersebut dapat dilihat oleh seluruh siswa. Aktifitas siswa hanya mengamati dan mendengarkan penjelasan guru. Siswa cenderung pasif untuk mengamati lebih dekat, dikarenakan waktu yang terbatas. Guru belum menggunakan LCD Proyektor dalam penyampaian materi dikarenakan LCD Proyektor sekolah dalam kondisi rusak. Keterbatasan alat peraga dalam penyampaian materi, mengakibatkan guru kurang optimal dalam menjelaskan materi, hanya menggunakan buku paket. Kondisi ini mengakibatkan siswa cenderung mengantuk, berbicara dengan siswa lain, bermain, dan selalu membuat kegiatan sendiri pada saat guru menjelaskan materi pembelajaran dengan metode ceramah, sehingga kondisi kelas tidak kondusif yang mengakibatkan kurangnya pemahaman siswa mengenai materi pembelajaran yang telah disampaikan oleh guru yang pada akhirnya berpengaruh terhadap hasil belajar siswa.

Oleh sebab itu, media pembelajaran perlu dioptimalkan dalam pembelajaran IPA karena materi IPA sulit untuk dipahami siswa jika disajikan dalam bentuk buku cetak, dan metode ceramah saja. Media juga perlu dioptimalkan dengan penggunaan teknologi agar lebih bervariatif dan menyenangkan, terlebih di sekolah telah disediakan sarana berupa komputer dan LCD Proyektor pada ruang komputer. Media hendaknya memberikan pengalaman langsung kepada siswa sehingga berdampak positif terhadap hasil belajar siswa, terlebih saat ini telah mencapai perkembangan abad ke 21. Smaldino dkk (2014) menyatakan bahwa "dasar untuk pengetahuan dan keterampilan abad 21 adalah persiapan peserta didik untuk pembelajaran bermakna dan sengaja 
untuk menggunakan teknologi dan media untuk kreatifitas, inovasi, komunikasi, penelitian dan pemecahan masalah". Media berbasis teknologi penting diberdayakan dalam kegiatan pembelajaran sekolah, baik di kota maupun di desa.

Guru juga memiliki peran penting dalam menciptakan kegiatan pembelajaran yang berkualitas baik di perkotaan maupun di pedesaan. Setiap orang yang berkecimpung dalam Jurusan Teknologi Pendidikan pun hendaknya memberikan kontribusi dalam pemecahan masalah pendidikan di Indonesia. Miarso (2011) mengemukakan bahwa "Teknologi Pendidikan didefinisikan sebagai suatu kajian dan praktis etis dalam memfasilitasi belajar, dan meningkatkan kinerja, melalui penciptaan, penggunaan dan pengelolaan proses dan sumber teknologikal yang tepat guna. Secara operasional, teknologi pendidikan dapat dikatakan sebagai proses yang bersistem dalam membantu memecahkan masalah belajar pada manusia". Untuk memecahkan masalah pada mata pelajaran IPA kelas IX di SMP N 5 Panyabungan, yaitu melalui inovasi pengembangan media pembelajaran berupa multimedia interaktif. Multimedia merupakan kombinasi dari teks, gambar, video, suara, dan animasi. Multimedia interaktif yang akan dikembangkan berupa gabungan kombinasi software Power Point, Ispring suite 9, Adobe Photoshop, Camtasia, Powtoon, dan Form Google Doc. Software tersebut mendukung pengembangan multimedia interaktif yang berisi teks, gambar, video, suara dan animasi. Penggunaan multimedia interaktif memiliki tujuan untuk memberikan motivasi kepada siswa, merangsang siswa untuk mengingat apa yang sudah dipelajari. Selain memberi rangsangan belajar, multimedia interaktif juga menumbuhkan kebiasaan untuk mengulangi pelajaran, dan diharapkan akan memberikan pengaruh postif terhadap hasil belajar siswa.

Ispring suite 9 merupakan software yang dapat digunakan dalam pembelajaran yang terintegrasi dengan perangkat lunak Microsoft Power Point. Software ini merupakan salah satu tool yang mengubah file presentasi menjadi bentuk flash. Penggunaan ispring suite 9 ini, akan menciptakan multimedia interaktif yang berisikan media gambar, teks, audio, video, serta animasi yang mampu menumbuhkan motivasi siswa, serta memberikan pengalaman langsung kepada siswa dalam mempelajari materi IPA yang cenderung bersifat abstrak, sehingga berpengaruh terhadap peningkatkan hasil belajar siswa.

\section{METODE PENELITIAN}

Penelitian ini menggunakan metode penelitian dan pengembangan (Research and Depelopment/R\&D). Menurut Sugiyono (2017) menyatakan bahwa $R \& D$ merupakan metode penelitian yang berfungsi untuk menguji, mengembangkan, dan menciptakan produk tertentu. Penelitian ini mengembangkan sebuah produk berupa multimedia interaktif yang menggunakan aplikasi Ispring suite 9, dan pengembangan aplikasi ini menggunakan model pengembangan ADDIE. Tegeh (2014) mengemukakan "Model ADDIE mudah dipahami dan diimplementasikan untuk mengembangkan produk pengembangan seperti bahan ajar, modul pembelajaran, video pembelajaran, multimedia dan lain sebagainya". Model ini memiliki lima tahapan yaitu, analisis (analyze), perancangan (design), pengembangan (development), implementasi (implementation), evaluasi (evaluation). Pemilihan model pengembangan ini dikarenakan, model ADDIE mengarahkan untuk melakukan pembelajaran secara berurutan dan interaktif dan pada setiap tahapan dilakukan evaluasi.

Tahap analisis (Analyze) Tahap analisis meliputi kegiatan berupa: a) Melakukan analisis kompetensi yang dituntut kepada siswa, b) Melakukan analisis karakteristik siswa tentang kapasitas belajarnya, pengetahuan, keterampilan, dan sikap yang telah dimiliki siswa. c) Melakukan analisis materi sesuai dengan tuntutan kompetensi. Melalui tahapan analisis ini, dapat dilakukan analisis melalui kurikulum, Silabus, RPP, yang berisikan SK, KD, serta indikator pencapaian pembelajaran siswa pada mata pelajaran IPA kelas IX.

Tahap selanjutnya adalah tahap perancangan (design). Tahap perancangan dilakukan dengan kerangka acuan sebagai berikut: a) Untuk siapa pembelajaran dirancang, b) Kemampuan apa yang diinginkan untuk dipelajari (kompetensi) c) Bagaimana materi pelajaran atau keterampilan dapat dipelajari (strategi pembelajaran), d) Bagaimana menentukan tingkat penguasaan pembelajaran yang sudah dicapai (assesmen atau evaluasi). Melalui tahapan ini, perancangan dapat dilakukan dengan merancang pembelajaran dilakukan untuk siswa kelas IX 
SMP, dan pembelajaran mengarah kepada ketercapaian tujuan pembelajaran, serta perancangan pembelajaran yang efisien yang hendak dilakukan di kelas sesuai dengan materi, sampai kepada membuat rancangan penilaian tes kemampuan pada siswa serta merancang flowchart dan storyboard.

Tahap ketiga adalah kegiatan pengembangan yang pada intinya adalah kegiatan menerjemahkan spesifikasi desain kedalam bentuk fisik, sehingga kegiatan ini menghasilkan gambaran produk pengembangan yang sesuai. Selanjutnya membuat produk yang dikembangkan dengan software Ispring suite 9 with Power Point dan dibantu oleh program lainnya seperti Software Powtoon, Camtasia, adobe photoshop. Setelah itu melakukan uji coba produk yang dkembangkan yang sebelumnya telah divalidasi oleh ahli. Validasi ahli terdiri dari 3 ahli yaitu ahli materi, ahli media dan ahli bahasa dengan menggunakan skala likert.

Tahap selanjutnya yaitu uji pengembangan terdiri dari uji praktikalitas untuk siswa dan guru bertujuan untuk mengukur seberapa praktis produk pengembangan yang dibuat dan Uji efektivitas hasil belajar melalui uji Paired Sample T-test dan gain test. Analisis Paired Sample Ttest dilakukan dengan aplikasi SPSS untuk melakukan uji $\mathrm{T}$ terhadap data pre-test dan post test. Teknik analisis data gain-test dilakukan dengan menghitung nilai gain (g) untuk mengetahui peningkatan pemahaman siswa.

\section{HASIL DAN PEMBAHASAN}

Penelitian ini menggunakan model pengembangan ADDIE pada setiap tahapnya dan menghasilkan produk multimedia interaktif menggunakan ispring suite 9 pada pembelajaran IPA yang layak, praktis dan efektif.

\section{asil Uji Validitas}

Desain awal multimedia interaktif menggunakan aplikasi ispring suite 9 sebelum diuji cobakan harus divalidasi terlebih dahulu oleh para ahli. Tujuannya adalah untuk mengetahui kelayakan desain awal multimedia interaktif menggunakan aplikasi ispring suite 9 tersebut. Validasi ini dilakukan oleh dosen ahli yang terdiri dari dosen ahli materi, dosen ahli media, dosen ahli bahasa. Dari uraian hasil validasi pada ahli dan uji pengembangan multimedia interaktif menggunakan ispring suite 9 pada pembelajaran IPA dapat disimpulkan pada tabel 1.

Tabel 1. Rekapitulasi Penilaian Validitas

\begin{tabular}{|l|l|l|l|}
\hline No. & Uraian & Skor & Kategori \\
\hline 1 & Materi & 96 & Sangat Valid \\
\hline 2 & Media & 88 & Sangat Valid \\
\hline 3 & Bahasa & 82,5 & Valid \\
\hline
\end{tabular}

Berdasarkan kategori kevalidan, hasil validitas pengembangan multimedia interaktif menggunakan aplikasi ispring suite 9 termasuk kategori sangat valid. Setelah multimedia interaktif menggunakan ispring suite 9 dinyatakan sangat valid, dan mendapat saran perbaikan oleh validator, sebelum penerapan produk secara menyeluruh dilakukan perbaikan terhadap produk yang dikembangkan agar mendapat data praktikalitas sesuai dengan tujuan penelitian.

Adapun revisi dan saran yang disampaikan oleh para dosen ahli terhadap media yang dikembangkan adalah sebagai berikut:

1. Revisi Ahli Materi

Ditinjau dari aspek materi, pada multimedia interaktif menggunakan aplikasi ispring suite 9 terdapat saran perbaikan dari validator pada bagian perbaikan terhadap penyusunan materi yang lebih terurut agar siswa mudah memahami materi, serta penyampaian materi menggunakan bahasa yang lebih baku dan mudah dipahami oleh siswa.

2. Revisi Ahli Media

Ditinjau dari aspek media, pada multimedia interaktif menggunakan aplikasi ispring suite 9 terdapat saran perbaikan dari validator pada beberapa bagian, yaitu:

a. Instrumen musik agar dapat diganti dengan audio dubbing dari teks yang muncul pada media. 
b. Akan lebih baik jika pada peta konsep bisa di link kan ke halaman terkait.

3. Revisi Ahli Bahasa

Ditinjau dari aspek bahasa, pada multimedia interaktif menggunakan aplikasi ispring suite 9 terdapat saran perbaikan serta pendapat dari validator pada beberapa bagian, yaitu:

a. Media mudah dipahami, namun lebih baik untuk menyusun kembali agar kata tidak berjarak jauh agar lebih rapi.

b. Kalimat yang digunakan seperti komik, hal ini sangat baik sehingga lebih mudah dipahami siswa.

\section{Hasil Uji Praktikalitas}

Penilaian praktikalitas siswa dilakukan terhadap 30 orang siswa kelas IX.3 SMP Negeri 5 Panyabungan. Penilaian mencakup 11 aspek penilaian. Berdasarkan hasil uji praktikalitas siswa, maka didapat rata-rata praktikalitas multimedia interaktif menggunakan aplikasi ispring suite 9 sebesar 90\% dengan kategori sangat praktis. Penilaian praktikalitas guru oleh guru IPA kelas IX SMP Negeri 5 Panyabungan mencakup 11 aspek penilaian. Berdasarkan hasil uji praktikalitas guru, maka didapat rata-rata praktikalitas multimedia interaktif menggunakan aplikasi ispring suite 9 sebesar 95\% dengan kategori sangat praktis. Dari uraian hasil praktikalitas pengembangan multimedia interaktif menggunakan aplikasi ispring suite 9 dapat disimpulkan pada tabel 2 .

\section{Tabel 2. Rekapitulasi Penilaian Praktikalitas}

\begin{tabular}{|c|l|l|l|}
\hline No. & Uraian & Skor & Kategori \\
\hline 1 & Siswa & 90 & Sangat Valid \\
\hline 2 & Guru & 95 & Sangat Valid \\
\hline
\end{tabular}

Sumber: Olahan Data.

Berdasarkan kategori kepraktisan, hasil praktikalitas siswa dan guru termasuk ke dalam kategori sangat praktis.

\section{Hasil Uji Efektivitas}

Uji efektivitas ini dilakukan untuk mengetahui peningkatan pemahaman siswa mengenai mata pelajaran IPA melalui pembelajaran multimedia interaktif menggunakan ispring suite. Uji efektivitas dilakukan dengan memberikan pretest dan postest terhadap siswa. Data uji efektivitas diuji dengan program SPSS Statistic 16 (Statistic Product for Service Solution) dengan menggunakan Paired Sample T-Test dan penghitungan nilai gain.

a. Uji T-Test

Tabel 3. Hasil Perbandingan Pretest dan Postest

\begin{tabular}{|ll|l|l|l|l|}
\hline & & Mean & N & Std. Deviation & Std. Error Mean \\
\hline Pair 1 & Pre Test & 54,27 & 30 & 7,84 & 1,43 \\
& Post Test & 83,34 & 30 & 6,22 & 1,14 \\
\hline
\end{tabular}

Perbandingan statistik pada pretest dan posttest yang menunjukkan bahwa rata rata skor pretest siswa adalah sebesar 54,27 dengan standar deviasi 7,84 sedangkan rata-rata skor posttest siswa adalah sebesar 83,34 dengan standar deviasi sebesar 6,22. Berdasarkan analisis pada paired samples statistic tersebut maka dapat dilihat bahwa terdapat kenaikan rata-rata skor pretest dan posttest siswa sebesar 29,07.

Berdasarkan tabel 4, dapat diuji perbedaan rata- rata skor pretest dan posttest siswa adalah 29,07 . Nilai $t$ yang diperoleh adalah sebesar 16,16 dengan signifikansi 0,00. Karena nilai signifikansi $0,00<0,05$ maka dapat disimpulkan bahwa terdapat perbedaan antara nilai pretest dan posttest pada siswa. 
Tabel 4. Uji Perbedaan Prestest dan Posttest

\begin{tabular}{|ll|l|l|l|l|l|l|}
\hline \multirow{2}{*}{} & \multicolumn{2}{|l|}{ Paired Differences } & & & \\
\cline { 2 - 6 } & Mean & $\begin{array}{l}\text { Std. } \\
\text { Deviation }\end{array}$ & $\begin{array}{l}\text { Std. Error } \\
\text { Mean }\end{array}$ & $\begin{array}{l}\text { Sig. } \\
\text { tailed })\end{array}$ \\
\hline Pair 1 & $\begin{array}{l}\text { Pretest } \\
\text { Posttest }\end{array}$ & $-29,07$ & 9,85 & 1,80 & $-16,16$ & 29 & 000 \\
\hline
\end{tabular}

\section{b. Perhitungan Gain Score}

Untuk mengetahui peningkatan pemahaman siswa, maka diukur dengan menggunakan nilai gain. Diketahui bahwa rata-rata skor posttest siswa adalah sebesar 83,34 rata-rata skor pretest siswa adalah sebesar 54,27, dan skor maksimum siswa adalah 100,00. Dari data tersebut, maka perhitungan nilai gain-nya adalah 0,63 sehingga kriteria nilai gain menurut Hake adalah Sedang. Hal ini menunjukkan kemampuan multimedia interaktif menggunakan ispring suite 9 dalam meningkatkan pemahaman siswa.

\section{Pembahasan \\ Validitas Multimedia Interaktif menggunakan aplikasi Ispring suite 9 pada Mata Pelajaran IPA Kelas IX SMP}

Hasil uji validitas dari aspek materi, hasil validasi memperoleh rata-rata $96 \%$ kriteria sangat valid. Materi yang digunakan sudah sesuai dengan RPP dan Silabus yang berdasarkan pada pembelajaran. Validasi aspek media memperoleh rata-rata $88 \%$ dengan kriteria sangat valid. Kriteria sangat valid karena media yang dikembangkan sudah sesuai dengan prinsip media pembelajaran dan seluruh program yang terdapat pada media berjalan dengan baik. Sedangkan dari aspek bahasa, juga didapatkan hasil validasi menunjukkan rata-rata $82,5 \%$ dengan kriteria valid.

\section{Pratikalitas Multimedia Interaktif menggunakan aplikasi Ispring suite 9 pada Mata Pelajaran IPA Kelas IX SMP}

Hasil uji praktikalitas penggunaan Multimedia Interaktif menggunakan aplikasi Ispring suite 9 pada mata pelajaran IPA Kelas IX SMP oleh responden yang meliputi aspek tampilan, penyajian materi, dan kemanfaatan diperoleh skor rata-rata sebesar $90 \%$ dengan kategori sangat praktis. Hasil uji praktikalitas penggunaan penggunaan Multimedia Interaktif menggunakan aplikasi Ispring suite 9 pada mata pelajaran IPA dilakukan dengan melibatkan 1 orang guru mata pelajaran IPA SMPN 5 Panyambungan. meliputi aspek tampilan, penyajian materi, dan kemanfaatan diperoleh skor rata-rata sebesar 95\%. Penelitian ini juga didukung dengan data empiris yang menunjukan bahwa hasil praktikalitas penggunaan penggunaan Multimedia Interaktif menggunakan aplikasi Ispring suite 9 pada Mata Pelajaran IPA dengan kategori sangat praktis.

\section{Efektivitas Multimedia Interaktif menggunakan aplikasi Ispring suite 9 pada Mata Pelajaran IPA Kelas IX SMP}

Hasil uji efektifitas dengan menggunakan pretest dan posttest pada satu kelompok siswa kelas IX.3 yang berjumlah 30 orang menunjukkan bahwa rata rata skor pretest siswa adalah sebesar 54,27 dengan standar deviasi 7,84 sedangkan rata-rata skor posttest siswa adalah sebesar 83,34 dengan standar deviasi sebesar 6,22. terdapat kenaikan rata-rata skor pretest dan posttest siswa sebesar 29,07. Penelitian ini juga didukung dengan data empiris analisis pada Paired Samples Test Nilai t yang diperoleh adalah sebesar 16,16 dengan signifikansi 0,00. Karena nilai signifikansi $0,00<0,05$ maka dapat disimpulkan bahwa terdapat perbedaan antara nilai pretest dan posttest pada siswa. Dengan demikian terdapat perbedaan signifikan terhadap hasil pretest dan posttest. 


\section{Kesimpulan}

\section{KESIMPULAN, IMPLIKASI DAN SARAN}

Berdasarkan penelitian dan pengembangan multimedia interaktif menggunakan aplikasi ispring suite 9 pada mata pelajaran IPA kelas IX SMP disimpulkan beberapa hal sebagai berikut: 1) Pengembangan multimedia interaktif menggunakan aplikasi ispring suite 9 pada mata pelajaran IPA kelas IX SMP dikembangkan dengan model ADDIE yang dilakukan melalui 5 tahap yaitu tahap analyze, design, develop, implementation dan evaluation; 2) Hasil validitas multimedia interaktif menggunakan aplikasi ispring suite 9 pada mata pelajaran IPA kelas IX SMP. Validasi materi sebesar $96 \%$ menunjukkan kriteria sangat valid, validasi media sebesar $88 \%$ menunjukkan kriteria sangat valid, dan validasi bahasa sebesar $82,5 \%$ menunjukkan kriteria valid, validasi oleh ahli dilakukan perbaikan sebanyak satu kali; 3) Hasil uji praktikalitas penggunaan mobile learning berbasis android untuk praktikalitas siswa sebesar $90 \%$ menunjukkan kriteria sangat praktis serta praktikalitas guru sebesar $95 \%$ menunjukkan kriteria praktis setelah dilakukan penilaian kepraktisan; 4) Hasil efektivitas produk pengembangan multimedia interaktif menggunakan aplikasi ispring suite 9 pada mata pelajaran IPA kelas IX SMP menunjukkan kriteria efektif. Hasil belajar siswa berdasarkan pretest dan posttest diuji menggunakan rumus $\mathrm{T}$ Paired didapat nilai Nilai t yang diperoleh adalah sebesar 16,16 dengan signifikansi 0,00. Karena nilai signifikansi $0,00<0,05$ maka dapat disimpulkan bahwa terdapat perbedaan antara nilai pretest dan posttest pada siswa.

\section{Implikasi}

Berdasarkan temuan hasil penelitian maka implikasi pada penelitian dan pengembangan ini adalah sebagai berikut : 1) Penggunaan multimedia interaktif menggunakan aplikasi ispring suite 9 pada mata pelajaran IPA kelas IX SMP memerlukan sarana berupa perangkat komputer atau laptop yang dapat diakses secara offline; 2) Penggunaan multimedia interaktif menggunakan aplikasi ispring suite 9 pada mata pelajaran IPA kelas IX SMP memerlukan kemampuan dalam menggunakan perangkat komputer ataupun laptop baik bagi siswa maupun guru; 3) Pengembangan multimedia interaktif menggunakan aplikasi ispring suite 9 pada mata pelajaran IPA kelas IX SMP perlu menganalisis karakteristik siswa dan mendesain multimedia interaktif berbasis ispring suite 9 yang komunikatif sehingga dapat meningkatkan motivasi belajar siswa dan mencapai tujuan pembelajaran; 4) Pengembangan multimedia interaktif menggunakan aplikasi ispring suite 9 pada mata pelajaran IPA kelas IX SMP dalam pembelajaran harus memperhatikan aspek validitas, praktikalitas, dan efektivitas karena faktor ini sangat menentukan kualitas media pembelajaran yang dibuat untuk dapat digunakan dalam proses pembelajaran; 5) Multimedia interaktif menggunakan aplikasi ispring suite 9 pada mata pelajaran IPA kelas IX SMP dapat dipertimbangkan untuk digunakan sebagai media dalam pembelajaran karena dapat meningkatkan aktivitas dan hasil belajar siswa.

\section{Saran}

Berdasarkan hasil dan pembahasan penelitian pengembangan dapat disarankan hal-hal berikut: 1) Multimedia interaktif menggunakan aplikasi ispring suite 9 ini perlu dikembangkan lebih lanjut untuk materi-materi yang lainnya; 2) Multimedia interaktif menggunakan aplikasi ispring suite 9 ini perlu dikembangkan lebih lanjut mengenai tampilan, sehingga dapat memuat animasi bergerak; 3) Multimedia interaktif menggunakan aplikasi ispring suite 9 ini dapat digunakan sebagai sarana belajar materi IPA kelas IX SMP.

\section{DAFTAR PUSTAKA}

Kemendikbud. (2005). Permendikbud No. 19 Tahun 2005 pada bab 4 tentang Standar Nasional Pendidikan mengenai standar proses. Jakarta: Kemendikbud. Diunduh tangal 2 September 2019.

Kemendikbud. (2006). Permendikbud No. 22 Tahun 2006 Tentang Pembelajaran IPS SMP/MTs. Jakarta: Kemendikbud. Diunduh tangal 2 September 2019.

Smaldino, S., Lowther, D. L., \& Rusell, J. D. (2014). Instructional Technology and Media For Learning (Edisi Sepuluh ed.). New York: Macmillan Publishing Company. 
Sugiyono. (2017). Metode Penelitian \& Pengembangan (Research and Development /R\&D) untuk Bidang Pendidikan, Manajemen, Sosial, Teknik. Bandung: Alfabeta.

Tegeh, I. M., Jampel, I. N., \& Pudjawan, K. (2014). Model Penelitian Pengembangan (Edisi Pertama ed.). Yogyakarta: Graha Ilmu.

Undang-undang Negara Republik Indonesia. (2003). Undang-Undang No. 20 Tahun 2003 Tentang Sistem Pendidikan Nasional. Diunduh tangal 2 September 2019.

Yusuf Hadi Miarso (2011). Menyemai Benih Teknologi Pendidikan. Jakarta: Kencana 